\title{
Prenatal Prediction of Poor Maternal and Offspring Outcomes: Implications for Selection into Intensive Parent Support Programs
}

\author{
Catherine R. Chittleborough • Debbie A. Lawlor • \\ John W. Lynch
}

Published online: 15 May 2011

(c) The Author(s) 2011. This article is published with open access at Springerlink.com

\begin{abstract}
This study examined the predictive ability of mother's age, antenatal depression, education, financial difficulties, partner status, and smoking for a range of poor maternal and offspring outcomes assessed up to 61 months postnatally. Outcomes obtained from the Avon Longitudinal Study of Parents and Children (ALSPAC) were maternal postnatal depression at 8 weeks $(n=10,070)$, never breastfeeding $(\mathrm{n}=7,976)$, feelings of poor attachment $(\mathrm{n}=8,253)$ and hostility $(\mathrm{n}=8,159)$ at 47 months, and not in employment, education or training (NEET, $\mathrm{n}=8,265$ ) at 61 months. Only a small proportion of women with each outcome were aged less than 20 years when they were pregnant. At least half of the women experiencing these outcomes, and up to $74.7 \%$ of women
\end{abstract}

Electronic supplementary material The online version of this article (doi:10.1007/s10995-011-0818-5) contains supplementary material, which is available to authorized users.

C. R. Chittleborough $(\bowtie) \cdot$ D. A. Lawlor · J. W. Lynch School of Social and Community Medicine, University of Bristol, Canynge Hall, Whatley Road, Bristol BS8 2PS, UK e-mail: catherine.chittleborough@bristol.ac.uk

C. R. Chittleborough · J. W. Lynch

School of Population Health and Clinical Practice, University

of Adelaide, Adelaide 5005, SA, Australia

D. A. Lawlor

MRC Centre for Causal Analysis in Translational Epidemiology, University of Bristol, Oakfield House, Oakfield Grove, Bristol BS8 2BN, UK

J. W. Lynch

Sansom Institute for Health Research, Division of Health

Sciences, University of South Australia, Adelaide,

SA 5001, Australia with postnatal depression, could be identified if they had at least one of the predictors measured during pregnancy (age $<20$, depression, education less than $\mathrm{O}$ level, financial difficulties, no partner, or smoking). Model discrimination was poor using maternal age only (area under the receiver operator characteristic (AUROC) curve approximately 0.52), except for never breastfeeding (0.63). Discrimination improved (AUROC: 0.80, 0.69, 0.62, 0.60, 0.66 for depression, never breastfeeding, poor attachment, hostility and NEET, respectively) when all six predictors were included in the model. Calibration improved for all outcomes with the model including all six predictors, except never breastfeeding where even age alone demonstrated good calibration. Factors other than young maternal age, including education, smoking and depression during pregnancy should be considered in identifying women and their offspring likely to benefit from parenting support interventions.

Keywords ALSPAC Maternal age $\cdot$ Maternal health services $\cdot$ Predictive value of tests

\section{Introduction}

The provision of universal family support services, with additional support for those with greater needs (a concept known as progressive universalism), underpins many maternal and child health services. This was the lead recommendation of the recent Marmot Review to give every child the best start in life and thereby reduce health inequalities $[1,2]$. Policies to improve parenting support aim to enhance health and development of children, improve maternal physical and mental health, strengthen parent-child attachment and positive parenting, and 
increase rates of initiation and continuation of breastfeeding [2-5]. An additional goal of the US Nurse Family Partnership and the UK Family Nurse Partnership (FNP) is to improve the economic self sufficiency of vulnerable parents by helping them space future pregnancies, complete education and find work [6, 7].

Identifying families who would benefit from programs beyond universal services is a challenging balance of efficient use of limited resources, against risk of stigmatising some mothers as less able parents [8]. Young maternal age is often used to define families eligible for extended services [2, 6, 9], due to the association of young motherhood with many other factors that may increase risk of poorer child and maternal outcomes, and the belief that it is less stigmatizing than focusing on these other risk factors directly [10]. For instance, teenage mothers are often from lower socioeconomic backgrounds and both teenage mothers and mothers on low income report increased rates of depressive symptoms [11, 12]. Children of mothers who are depressed are at increased risk of poorer development and behaviour [13]. Depressed mothers tend to report feeling less attached to [14, 15], and have more hostile feelings toward, their children [15], although the long-term risks of poor attachment for child development remains unclear [16]. Socioeconomic environment and maternal education may also influence the effect of maternal depression on child well being and development $[17,18]$. Breastfeeding is associated with many short- and long-term benefits for both the mother and child [19], and young maternal age, low education, and depressive symptoms are associated with poor breastfeeding outcomes [20, 21]. Thus, there is evidence that young maternal age is associated with a cascade of other factors that may increase risk for poorer child and maternal outcomes. However, it is also known that risk factors, even causal ones, are not necessarily good predictors of outcomes [22].

The aim of this study was to examine the predictive validity of young maternal age ( $<20$ years) alone and then to include measures of antenatal depression, maternal education, financial difficulties, partner status, and smoking during pregnancy, for a range of poor maternal and offspring outcomes up to 61 months. We compared three prediction models: (1) young maternal age only (to reflect current practice in the UK and some other countries); (2) antenatal depression only (as this is likely to be related to postnatal depression and other outcomes) and (3) all six antenatal predictors (chosen as representing characteristics that are, or could be, obtained by practitioners during the antenatal period). This work builds on a previous study examining predictors of poor child development, which showed that using all six characteristics provided better prediction of poor child outcomes than maternal age alone [23].

\section{Methods}

Sample

The Avon Longitudinal Study of Parents and Children (ALSPAC) is a prospective, geographically representative study of children born to women resident in the Avon area of southwest England with an expected delivery date between 1st April 1991 and 31st December 1992. Details of the background, methodology, recruitment and response rates have been reported elsewhere (http://www.bristol. ac.uk/alspac/) [24]. The core ALSPAC sample consists of 14,541 pregnancies (Fig. 1). Ethical approval was obtained from the ALSPAC Law and Ethics committee and local research ethics committees.

\section{Maternal Outcomes}

Ten items that formed the depression scale of the Edinburgh Postnatal Depression Scale (EPDS) [25-27] were administered to women via questionnaire when their baby was 8 weeks old. Each question had 4 response categories scored from 0 to 3 and referred to the feelings of the mother in the past week. A score above 12 is used to indicate probable depressive disorder [25].

Duration of breastfeeding was assessed in the questionnaire when the child was 6 months old. Never having breastfed the child was considered a poor outcome [28].

Poor attachment was assessed by the question "Very occasionally, mothers have mentioned that they felt quite unattached to their babies or even that they felt dislike for them for several weeks. Has this ever happened to you?" included in the questionnaire when the child was 47 months old. If mothers responded positively they were classified as having feelings of poor attachment. Mothers' feelings of hostility toward their child were also assessed in this questionnaire. Mothers were asked to respond yes (2), no (0), or sometimes (1) to the following three questions: I often get irritated by this child; I have frequent battles of will with this child; This child gets on my nerves. The scores for each question were summed and a total score of five or higher was defined as a high level of hostility [29].

Not in employment, education or training (NEET) was assessed in the questionnaire when their child was 61 months old. If mothers had not had a baby in those 5 years since their study child was born, and had not worked in the past year, or taken any courses or educational training in the past two years, they were classified as NEET. Women who had one or more babies after their study child was born were classified as not being NEET, irrespective of whether they were in employment, education or training, since these women would have had a 


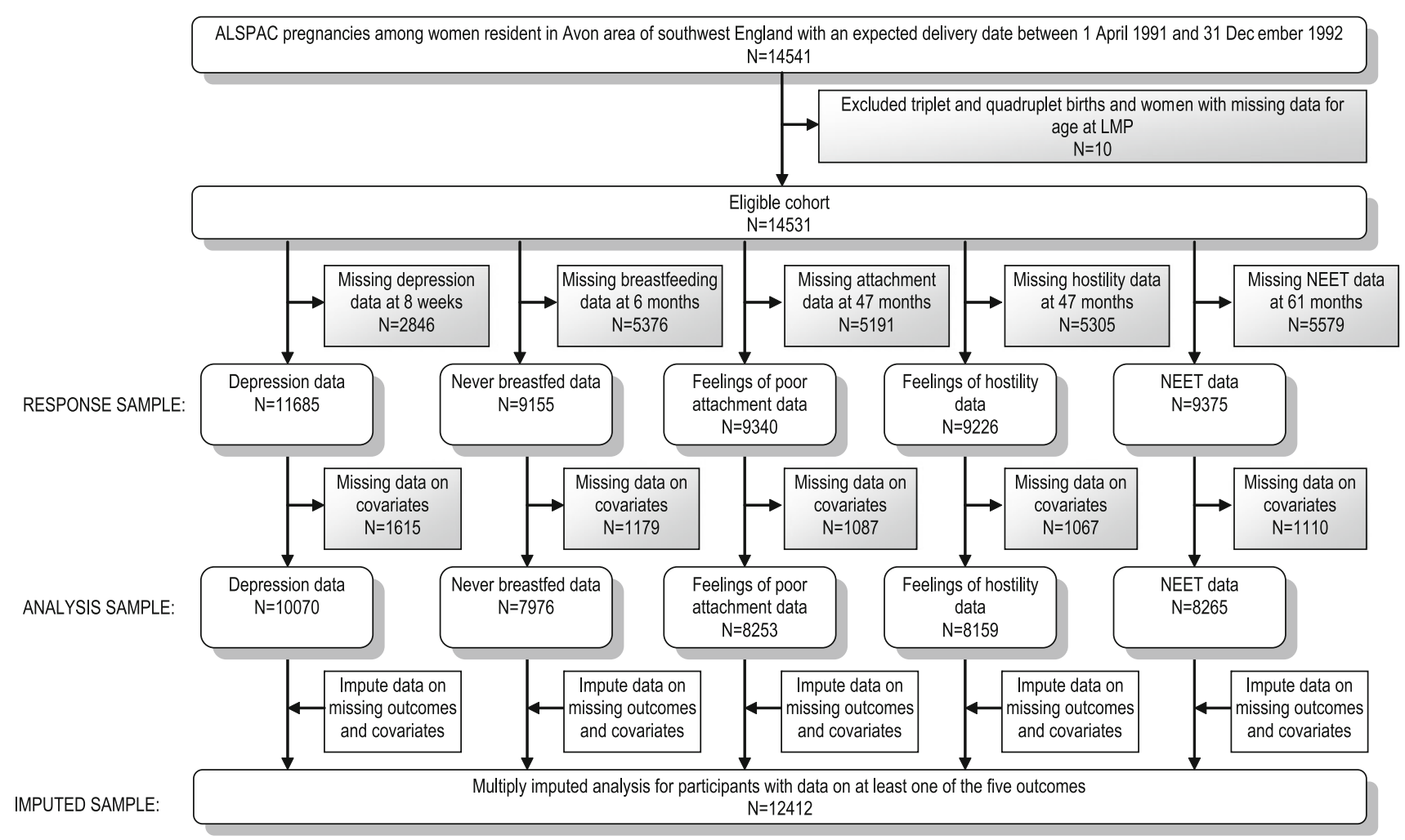

Fig. 1 Eligible cohort and numbers included for analyses. NEET not in employment, education or training, and not had a baby since study child

pre-school age child and this frequently results in voluntarily staying at home with the child(ren).

\section{Antenatal Predictors}

Age of mother at last menstrual period (LMP) was obtained for $\mathrm{n}=14,531$ women (Fig. 1). and dichotomised at younger than 20 years, the cut-point commonly used to identify mothers eligible for programs [6, 9].

Highest education level of mothers and whether they experienced financial difficulties were recorded in the questionnaire at 32 weeks gestation. Highest education level was categorised into: O level or higher (Ordinary level exams most commonly taken at age 16 years, the legal minimum age for leaving school in the UK); and less than $\mathrm{O}$ level. Financial difficulties was assessed from five questions asking how difficult at the moment the mother found it to afford food, clothing, heating, rent or mortgage, and things she will need for the baby, with a score of 1 (very difficult) to 4 (not difficult) for each response. The algorithm for calculating the overall financial difficulties score was 20 minus the sum of the scores of each of the five items, resulting in an overall score where 0 represented no financial difficulties and 15 the maximum financial difficulties. Participants with a score greater than 8 were defined as experiencing financial difficulties [30]. Partner status at study enrolment (married or cohabitating vs. no partner or not living with partner) was assessed by questionnaire. Whether or not they had smoked during the first 3 months of their pregnancy was measured in the questionnaire administered at 18-20 weeks gestation.

The EPDS was also administered to women via questionnaire at 18-20 weeks gestation. Although the measure was developed for use with women who have recently given birth, none of the ten items is specific to the postnatal experience and it has been validated for use during pregnancy [31, 32].

\section{Analysis}

We calculated the proportion of mothers with poor outcomes who had each of the individual binary predictive factors, and also who had at least one and at least two of the six binary predictors. Specificity, positive predictive value and likelihood ratio of each binary predictor were calculated (Supplemental Table 1). Univariable and multivariable (with mutual adjustment for all other predictors) logistic regression was used to examine the associations of predictors with each outcome. The predicted probability of each poor outcome was calculated from these logistic regression models. In clinical practice all of the predictors would likely be used as binary variables, however, calibration statistics cannot be easily interpreted using a single binary predictor so maternal age, financial difficulties and 
EPDS score were included as continuous variables in the prediction models.

The area under the receiver operator characteristic curve (AUROC) was used to assess the discriminatory capability of the models, or how accurately each model separates mothers into those with and without poor outcomes. Model 1 contained only maternal age, model 2 contained only antenatal EPDS score, and model 3 included all six predictors. An AUROC of 1 represents a model that perfectly discriminates the outcome, whereas an AUROC of 0.5 represents a prediction tool that is no better than chance at identifying those at risk. While calibration statistics are not possible with single binary variables, we did calculate the AUROC for all three models using predictors as binary variables, as would be more commonly used in clinical practice (Supplemental Table 2).

Calibration of the three models, or the agreement between observed and predicted outcomes, was assessed by ranking mothers into deciles of their predicted risk from each model and then comparing the predicted to observed proportion within each decile. The Hosmer-Lemeshow goodness-of-fit chi-square statistic was used to test the accuracy of calibration [33]. This statistic tests the null hypothesis that the predicted proportion equals the observed proportion within ranked groupings (deciles) of predicted risk. A high $P$ value suggests good calibration of predicted and observed risk.

The integrated discrimination improvement (IDI) [34] for model 2 or 3 in comparison to model 1 was also calculated. This assesses discrimination without relying on cut-off points and compares the average difference in predicted risk for women with and without poor outcomes. The IDI is greater when the second model correctly assigns individuals to higher or lower probabilities of having the outcome in comparison to the first model.

\section{Missing Data}

Analyses were conducted using participants with complete data on all six predictive factors $(\mathrm{N}=10,955)$ and the

Table 1 Prevalence and amount of data available for each outcome and potential predictor measured during pregnancy

\begin{tabular}{|c|c|c|c|c|c|c|c|c|}
\hline & \multirow{2}{*}{\multicolumn{2}{|c|}{$\begin{array}{l}\text { Response } \\
\text { sample* }\end{array}$}} & \multicolumn{5}{|c|}{ Analysis sample $^{\dagger}$} & \multirow{3}{*}{$\begin{array}{l}\text { Imputed } \\
\text { sample* }\end{array}$} \\
\hline & & & \multirow{2}{*}{$\begin{array}{l}\text { Depression, } \\
8 \text { weeks } \\
\mathrm{N}=10,070 \\
\%\end{array}$} & \multirow{2}{*}{$\begin{array}{l}\text { Never } \\
\text { breastfed } \\
\mathrm{N}=7,976 \\
\%\end{array}$} & \multirow{2}{*}{$\begin{array}{l}\text { Feelings of poor } \\
\text { attachment } \\
\mathrm{N}=8,253 \\
\%\end{array}$} & \multirow{2}{*}{$\begin{array}{l}\text { Feelings of } \\
\text { hostility, } 47 \mathrm{~m} \\
\mathrm{~N}=8,159 \\
\%\end{array}$} & \multirow{2}{*}{$\begin{array}{l}\text { NEET, } \\
61 \mathrm{~m} \\
\mathrm{~N}=8,265 \\
\%\end{array}$} & \\
\hline & $\mathrm{N}$ & $\%$ & & & & & & \\
\hline \multicolumn{9}{|l|}{ Outcome } \\
\hline Depression, 8 weeks & 11,695 & 10.1 & 9.6 & - & - & - & - & 10.4 \\
\hline Never breastfed & 9,155 & 26.8 & - & 25.8 & - & - & - & 26.7 \\
\hline $\begin{array}{l}\text { Feelings of poor } \\
\text { attachment }\end{array}$ & 9,340 & 7.0 & - & - & 6.9 & - & - & 7.2 \\
\hline $\begin{array}{l}\text { Feelings of hostility, } \\
47 \mathrm{~m}\end{array}$ & 9,226 & 14.6 & - & - & - & 14.4 & - & 14.9 \\
\hline NEET, $61 \mathrm{~m}$ & 9,375 & 6.9 & - & - & - & - & 6.7 & 7.3 \\
\hline \multicolumn{9}{|l|}{ Predictor } \\
\hline Age $<20$ years & 14,531 & 6.6 & 4.0 & 3.8 & 3.1 & 3.0 & 3.2 & 5.5 \\
\hline $\begin{array}{l}\text { No partner or not } \\
\text { cohabitating }\end{array}$ & 13,485 & 8.8 & 6.6 & 6.3 & 6.0 & 5.8 & 5.6 & 8.3 \\
\hline Financial difficulties & 12,011 & 10.0 & 9.2 & 9.4 & 8.4 & 8.3 & 8.6 & 9.3 \\
\hline Depression & 12,177 & 13.9 & 12.3 & 12.3 & 11.6 & 11.5 & 11.6 & 13.0 \\
\hline $\begin{array}{l}\text { Smoking in first } \\
3 \text { months }\end{array}$ & 13,189 & 25.1 & 21.8 & 22.2 & 20.5 & 20.3 & 20.4 & 24.0 \\
\hline $\begin{array}{l}\text { Education less than } \mathrm{O} \\
\text { level }\end{array}$ & 12,340 & 30.1 & 27.1 & 28.7 & 24.6 & 24.1 & 24.4 & 29.2 \\
\hline $\begin{array}{l}\text { At least } 1 \text { of the six } \\
\text { predictors }\end{array}$ & 10,955 & 51.2 & 49.3 & 50.6 & 46.3 & 46.0 & 46.3 & 57.1 \\
\hline $\begin{array}{l}\text { At least } 2 \text { of the six } \\
\text { predictors }\end{array}$ & 10,955 & 22.8 & 21.1 & 21.6 & 18.9 & 18.5 & 19.0 & 24.7 \\
\hline
\end{tabular}

NEET not in employment, education or training, and not had a baby since study child. * Response sample is the number who responded to specific questionnaire/assessment for each outcome or predictor. ${ }^{\dagger}$ Analysis sample includes respondents with complete data on the relevant outcome and all six predictors. ${ }^{\star}$ Imputed sample includes data imputed on outcomes or predictors for participants who provided data on at least one of the five maternal outcomes 
maternal outcome (Table 1, Fig. 1). Analyses were also conducted on an imputed data set to examine the influence of missing data on the findings. Multiple imputation by chained equation was used to impute missing data on outcomes and predictors for respondents who had data on at least one outcome ( $\mathrm{N}=12,412$, Fig. 1) using the 'ice' command in Stata [35]. The imputation model included all outcomes and predictors as well as predictors of 'missingness' - birth weight, social class categorised according to the UK Registrar General's classification from I (high managerial or professional) to $\mathrm{V}$ (unskilled manual workers), ethnicity (white versus non-white) and reaction to pregnancy (categorised from overjoyed to very unhappy). We generated 20 data sets and undertook 20 cycles of regression switching ('switching' the order in which variables with missing data have it imputed) [35]. The multiple multivariate imputation approach creates a number of copies of the data ( 20 copies here) in which missing values are imputed, with an appropriate level of randomness, by chained equations [35]. The results are obtained by averaging across the results from each of these 20 datasets using Rubin's rules and the procedure takes account of uncertainty in the imputation [35]. Results from the analyses using multiply imputed data are presented in Supplemental Tables 3 and 4.

\section{Results}

The prevalence of each outcome and predictor is listed in Table 1, which shows $51.2 \%$ of women had at least one, and $22.8 \%$ had at least two of the predictors. Table 2 shows the proportion of mothers with poor outcomes who had each antenatal characteristic. Only a small proportion of women with any of the five outcomes were aged less than 20 years when they were pregnant (3.9-7.3\%). More than half of the women with any of the poor outcomes, and up to $74.7 \%$ of women with postnatal depression, could be identified if information on all six predictors was used and a woman had at least one of these.

Maternal age less than 20 years was strongly associated with never breastfeeding and this association remained in multivariable analyses adjusted for all other factors (Table 3). Smoking during pregnancy was associated with all outcomes. Antenatal depression was strongly associated with postnatal depression, and feelings of poor attachment and hostility. Education less than $\mathrm{O}$ level was associated with never having breastfed and NEET, whereas mothers with a higher level of education were more likely to experience feelings of poor attachment.

Table 4 shows the discrimination (AUROC), and calibration for all models. Discrimination of all outcomes, with the exception of never breastfeeding, was poor using model 1 (maternal age only). Discrimination of postnatal depression was better with model 2 (antenatal depression score only) or model 3 (all six predictors) than it was with model 1 (age only). Model 2 (antenatal depression score only) was poor at discriminating the breastfeeding and NEET outcomes, but discrimination of these outcomes was better when model 3 (all six predictors) was used. In comparison to model 1 (maternal age only) discrimination of feelings of poor attachment and hostility were improved with model 2 , and more so when all six predictors were used (model 3). The Hosmer-Lemeshow goodness-of-fit tests indicated better calibration using model 3 (all six predictors) or model 2 (antenatal depression score only) than model 1 (maternal

Table 2 Proportion and cumulative proportion (for at least 1 or 2 of the predictors) of outcome cases that would be detected with maternal characteristics measured during pregnancy

\begin{tabular}{|c|c|c|c|c|c|}
\hline $\begin{array}{l}\text { Variable measured } \\
\text { during pregnancy }\end{array}$ & $\begin{array}{l}\text { Depression, } 8 \text { weeks } \\
(\mathrm{n}=10,070) \\
\%\end{array}$ & $\begin{array}{l}\text { Never breastfed } \\
(\mathrm{n}=7,976) \\
\%\end{array}$ & $\begin{array}{l}\text { Feelings of poor } \\
\text { attachment }(\mathrm{n}=8,253) \\
\%\end{array}$ & $\begin{array}{l}\text { Feelings of hostility, } \\
47 \mathrm{~m}(\mathrm{n}=8,159) \\
\%\end{array}$ & $\begin{array}{l}\text { NEET, } 61 \mathrm{~m} \\
(\mathrm{n}=8,265) \\
\%\end{array}$ \\
\hline Age $<20$ years & 6.5 & 7.3 & 4.2 & 3.9 & 4.0 \\
\hline $\begin{array}{l}\text { No partner or not } \\
\text { cohabitating }\end{array}$ & 11.7 & 9.9 & 6.9 & 7.2 & 11.7 \\
\hline Financial difficulties & 21.9 & 10.6 & 11.3 & 11.7 & 12.6 \\
\hline Depression & 43.0 & 14.6 & 18.7 & 17.4 & 14.8 \\
\hline $\begin{array}{l}\text { Smoking in first three } \\
\text { months }\end{array}$ & 34.9 & 31.6 & 25.7 & 25.6 & 31.0 \\
\hline $\begin{array}{l}\text { Education less than } \mathrm{O} \\
\text { level }\end{array}$ & 33.2 & 46.6 & 20.6 & 23.9 & 42.6 \\
\hline $\begin{array}{l}\text { At least } 1 \text { of the six } \\
\text { predictors }\end{array}$ & 74.7 & 67.1 & 50.4 & 51.6 & 65.0 \\
\hline $\begin{array}{l}\text { At least } 2 \text { of the six } \\
\text { predictors }\end{array}$ & 45.0 & 33.7 & 23.2 & 23.9 & 33.8 \\
\hline
\end{tabular}

NEET not in employment, education or training, and not had a baby since study child 


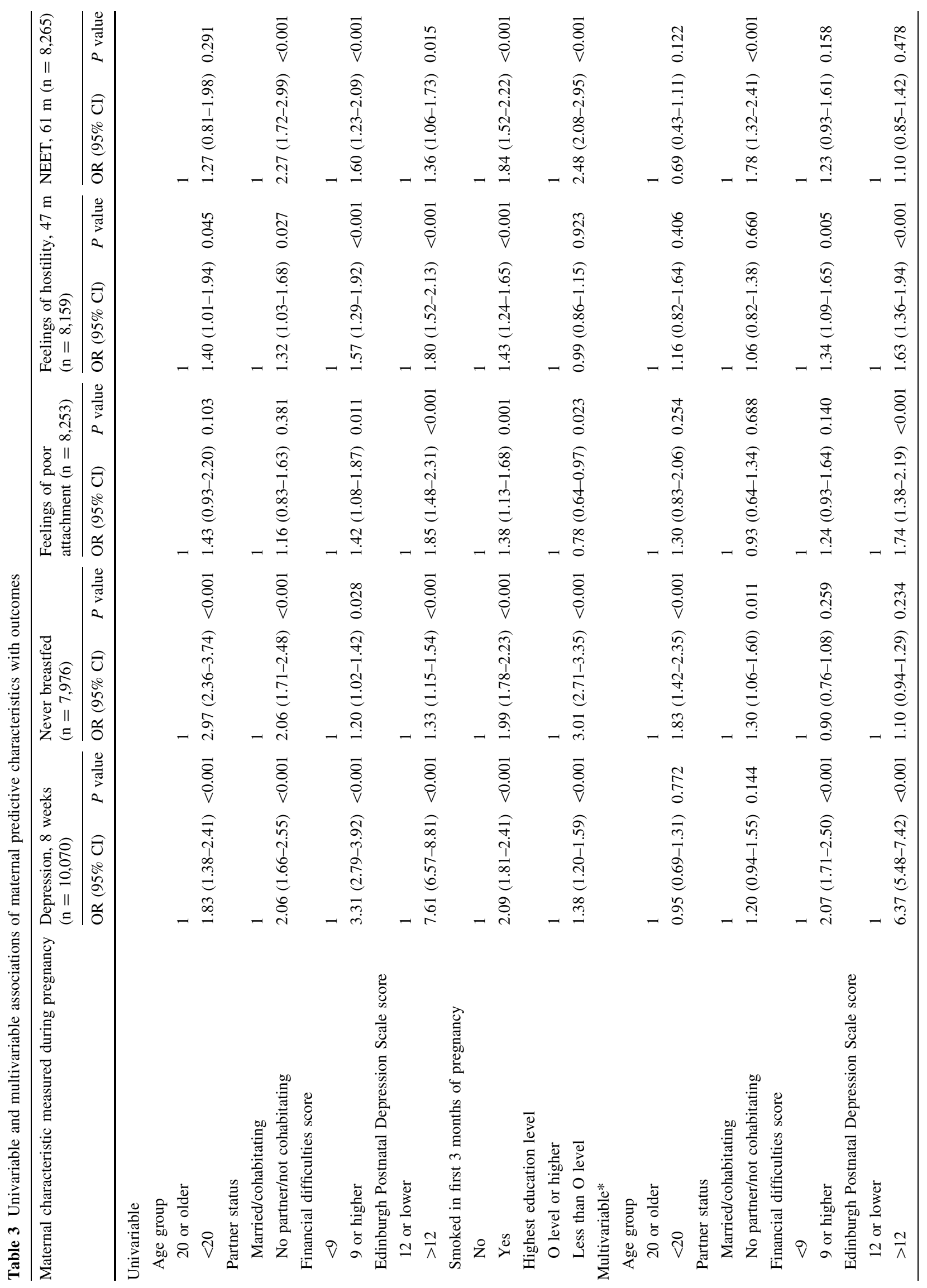


age only) for all outcomes with the exception of never breastfeeding where all models demonstrated good calibration, and feelings of hostility where model 2 had the worst calibration. Model 1 underestimated the likelihood of poor outcomes, with the exception of never breastfeeding, among those at highest risk (Table 4). The IDIs indicated that model 3 resulted in an improvement in calibration over model 1 , particularly for depression at 8 weeks and never breastfeeding, with approximately $15 \%$ and $4 \%$ of mothers being correctly reclassified by model 3 in comparison to model 1. Model 2 also resulted in an improvement in calibration over model 1 for postnatal depression.

Sensitivity Analyses

AUROC values calculated using all binary predictors (Supplemental Table 2) were lower but consistent with those obtained with a model that included continuous variables (Table 4). Associations between predictors and outcomes, and assessments of AUROC values using the multiply imputed dataset (Supplemental Tables 3 and 4) were consistent with analyses based on participants with complete data.

\section{Discussion}

Parent support interventions that may be effective at improving breastfeeding and return to employment, education or training, and reducing maternal postnatal depression and feelings of poor attachment and hostility are unlikely to have large impacts on these outcomes at the population level if young maternal age is used as the sole or main criteria for identifying eligible mothers. Only a small proportion of mothers with poor outcomes were teenagers, reflecting the small proportion of births to mothers aged 15-19 in most high income countries (e.g. 6.1\% in England and Wales in 2009 [36], 10.2\% in the US in 2006 [37] and $4.2 \%$ in Australia in 2008 [38]). Maternal age less than 20 years identified only $3-7 \%$ of later cases, depending on the maternal outcome studied. Maternal antenatal depression identified $43 \%$ of postnatal depression cases, and $15-19 \%$ of the other four outcomes.

Low education and smoking during pregnancy as single characteristics identified at least one-quarter and up to almost one-half of cases depending on the outcome. Smoking remained strongly associated with all maternal outcomes, even after adjusting for other characteristics, and is also more common (17\% of pregnant women in England in 2005 [39]) than teenage motherhood in the population. If information on all six predictors was collected during pregnancy, between half and three-quarters of cases of poor maternal and offspring outcomes would be identified using 
Table 4 Calibration and discrimination of the three models for each maternal outcome

\begin{tabular}{|c|c|c|c|c|c|c|c|c|c|}
\hline & \multicolumn{3}{|c|}{ Model 1 (maternal age) } & \multicolumn{3}{|c|}{ Model 2 (antenatal depression score) } & \multicolumn{3}{|c|}{ Model 3 (all six characteristics) } \\
\hline & Observed & Predicted & Ratio & Observed & Predicted & Ratio & Observed & Predicted & Ratio \\
\hline \multicolumn{10}{|l|}{ Depression, 8 weeks } \\
\hline Lowest 10th & 10.5 & 8.6 & 0.81 & 1.2 & 1.6 & 1.32 & 1.4 & 1.4 & 0.99 \\
\hline $2 \mathrm{nd}$ & 8.0 & 9.0 & 1.12 & 2.9 & 2.2 & 0.77 & 1.4 & 2.0 & 1.43 \\
\hline $3 \mathrm{rd}$ & 9.6 & 9.2 & 0.96 & 2.7 & 3.1 & 1.17 & 2.8 & 2.7 & 0.97 \\
\hline 4th & 8.5 & 9.4 & 1.10 & 4.2 & 4.3 & 1.04 & 3.4 & 3.5 & 1.04 \\
\hline 5 th & 9.0 & 9.5 & 1.05 & 4.6 & 5.4 & 1.17 & 4.0 & 4.6 & 1.14 \\
\hline 6 th & 8.4 & 9.7 & 1.15 & 7.1 & 6.6 & 0.94 & 5.6 & 6.0 & 1.07 \\
\hline 7 th & 9.5 & 9.9 & 1.04 & 8.9 & 9.1 & 1.01 & 8.2 & 8.0 & 0.97 \\
\hline 8th & 8.1 & 10.1 & 1.24 & 14.6 & 13.6 & 0.93 & 12.1 & 11.3 & 0.93 \\
\hline 9th & 9.8 & 10.3 & 1.05 & 21.1 & 19.6 & 0.93 & 20.0 & 17.9 & 0.90 \\
\hline Highest 10th & 13.6 & 10.7 & 0.79 & 37.0 & 37.7 & 1.02 & 36.8 & 38.3 & 1.04 \\
\hline Hosmer-Lemeshow chi-square* & \multicolumn{3}{|c|}{$20.17, P=0.028$} & \multicolumn{3}{|c|}{$7.39, P=0.689$} & \multicolumn{3}{|c|}{$7.36, P=0.692$} \\
\hline AUROC (95\% CI) & \multirow{2}{*}{\multicolumn{3}{|c|}{$0.5165(0.4967-0.5363)$}} & \multirow{2}{*}{\multicolumn{3}{|c|}{$\begin{array}{l}0.7918(0.7768-0.8069), P<0.001^{\dagger} \\
13.70(13.03-14.38), P<0.001^{*}\end{array}$}} & \multirow{2}{*}{\multicolumn{3}{|c|}{$\begin{array}{l}0.8025(0.7878-0.8172), P<0.001^{\dagger} \\
15.14(14.44-15.84), P<0.001^{*}\end{array}$}} \\
\hline IDI, \% (95\% CI) & & & & & & & & & \\
\hline \multicolumn{10}{|l|}{ Never breastfed } \\
\hline Lowest 10 th & 14.9 & 12.8 & 0.86 & 21.3 & 22.1 & 1.04 & 9.7 & 11.1 & 1.14 \\
\hline $2 \mathrm{nd}$ & 17.4 & 18.0 & 1.03 & 26.0 & 22.9 & 0.88 & 12.5 & 14.3 & 1.15 \\
\hline $3 \mathrm{rd}$ & 19.9 & 20.8 & 1.04 & 22.3 & 23.8 & 1.06 & 17.7 & 16.4 & 0.92 \\
\hline 4th & 22.2 & 22.5 & 1.01 & 25.0 & 24.6 & 0.99 & 18.3 & 18.2 & 0.99 \\
\hline 5 th & 24.4 & 24.3 & 1.00 & 25.5 & 25.2 & 0.99 & 18.9 & 20.2 & 1.07 \\
\hline 6th & 25.6 & 27.2 & 1.06 & 27.1 & 25.8 & 0.95 & 23.6 & 22.7 & 0.96 \\
\hline 7 th & 28.9 & 30.2 & 1.05 & 25.7 & 26.7 & 1.04 & 29.1 & 26.8 & 0.92 \\
\hline 8th & 32.1 & 32.4 & 1.01 & 30.2 & 28.0 & 0.93 & 36.3 & 33.1 & 0.91 \\
\hline 9th & 37.7 & 35.6 & 0.94 & 27.0 & 29.3 & 1.09 & 40.6 & 41.0 & 1.01 \\
\hline Highest 10th & 44.9 & 43.2 & 0.96 & 32.2 & 31.9 & 0.99 & 51.1 & 53.9 & 1.05 \\
\hline Hosmer-Lemeshow chi-square* & \multicolumn{3}{|c|}{$8.63, P=0.567$} & \multicolumn{3}{|c|}{$9.72, P=0.466$} & \multicolumn{3}{|c|}{$14.32, P=0.159$} \\
\hline AUROC (95\% CI) & \multirow{2}{*}{\multicolumn{3}{|c|}{$0.6266(0.6126-0.6407)$}} & \multirow{2}{*}{\multicolumn{3}{|c|}{$\begin{array}{l}0.5424(0.5279-0.5568), P<0.001^{\dagger} \\
-3.41(-3.81 \text { to }-3.01), P<0.001^{*}\end{array}$}} & \multirow{2}{*}{\multicolumn{3}{|c|}{$0.6858(0.6726-0.6991), P<0.001^{\dagger}$}} \\
\hline IDI, \% (95\% CI) & & & & & & & & & \\
\hline \multicolumn{10}{|l|}{ Feelings of poor attachment } \\
\hline Lowest 10th & 4.6 & 5.0 & 1.09 & 5.1 & 4.4 & 0.85 & 2.6 & 3.4 & 1.30 \\
\hline $2 \mathrm{nd}$ & 4.6 & 5.7 & 1.25 & 3.5 & 4.8 & 1.37 & 4.3 & 4.3 & 1.01 \\
\hline $3 \mathrm{rd}$ & 7.8 & 6.2 & 0.79 & 4.8 & 5.3 & 1.10 & 4.5 & 4.9 & 1.08 \\
\hline 4th & 7.0 & 6.5 & 0.93 & 5.5 & 5.9 & 1.07 & 6.1 & 5.4 & 0.88 \\
\hline 5 th & 5.3 & 6.8 & 1.29 & 7.6 & 6.3 & 0.83 & 6.3 & 5.9 & 0.93 \\
\hline 6th & 8.2 & 7.1 & 0.86 & 5.5 & 6.8 & 1.23 & 7.4 & 6.5 & 0.87 \\
\hline 7th & 6.8 & 7.3 & 1.08 & 7.9 & 7.4 & 0.94 & 6.7 & 7.2 & 1.08 \\
\hline 8th & 7.0 & 7.8 & 1.11 & 7.9 & 8.2 & 1.04 & 9.0 & 8.2 & 0.91 \\
\hline 9th & 9.5 & 8.4 & 0.88 & 10.1 & 9.3 & 0.92 & 8.4 & 9.6 & 1.15 \\
\hline Highest 10th & 9.3 & 9.5 & 1.02 & 12.1 & 12.5 & 1.04 & 13.6 & 13.5 & 1.00 \\
\hline Hosmer-Lemeshow chi-square* & \multicolumn{3}{|c|}{$14.51, P=0.151$} & \multicolumn{3}{|c|}{$9.58, P=0.478$} & $6.77, P=$ & & \\
\hline AUROC $(95 \% \mathrm{CI})$ & $0.5535(0$ & $5293-0.5777$ & & $0.6005(0.5$ & $0-0.6249)$, & $=0.004^{\dagger}$ & $0.6219(0$. & $4-0.6455)$, & $<0.001^{\dagger}$ \\
\hline IDI, \% (95\% CI) & & & & $0.65(0.48$ & 83), $P<0$. & & $1.13(0.90$ & 35), $P<0$. & \\
\hline Feelings of hostility, $47 \mathrm{~m}$ & & & & & & & & & \\
\hline Lowest 10th & 14.7 & 12.9 & 0.88 & 8.8 & 9.8 & 1.12 & 7.4 & 9.2 & 1.26 \\
\hline $2 \mathrm{nd}$ & 11.9 & 13.5 & 1.14 & 10.2 & 10.7 & 1.05 & 9.9 & 10.2 & 1.03 \\
\hline $3 \mathrm{rd}$ & 13.8 & 13.9 & 1.01 & 11.7 & 11.7 & 1.00 & 10.1 & 11.2 & 1.11 \\
\hline 4th & 12.7 & 14.2 & 1.11 & 11.1 & 12.8 & 1.14 & 12.7 & 11.9 & 0.93 \\
\hline
\end{tabular}


Table 4 continued

\begin{tabular}{|c|c|c|c|c|c|c|c|c|c|}
\hline & \multicolumn{3}{|c|}{ Model 1 (maternal age) } & \multicolumn{3}{|c|}{ Model 2 (antenatal depression score) } & \multicolumn{3}{|c|}{ Model 3 (all six characteristics) } \\
\hline & Observed & Predicted & Ratio & Observed & Predicted & Ratio & Observed & Predicted & Ratio \\
\hline 5 th & 13.1 & 14.4 & 1.10 & 17.3 & 13.5 & 0.78 & 14.2 & 12.8 & 0.90 \\
\hline 6 th & 14.4 & 14.6 & 1.01 & 13.7 & 14.3 & 1.05 & 14.6 & 13.8 & 0.95 \\
\hline 7 th & 17.1 & 14.8 & 0.86 & 15.0 & 15.6 & 1.04 & 16.7 & 15.0 & 0.90 \\
\hline 8 th & 13.9 & 15.1 & 1.08 & 19.0 & 17.0 & 0.89 & 17.9 & 16.5 & 0.92 \\
\hline 9 th & 16.7 & 15.5 & 0.92 & 20.5 & 18.8 & 0.92 & 17.3 & 18.8 & 1.09 \\
\hline Highest 10th & 17.4 & 16.2 & 0.93 & 21.8 & 23.9 & 1.10 & 23.2 & 24.4 & 1.05 \\
\hline Hosmer-Lemeshow chi-square* & \multicolumn{3}{|c|}{$12.40, P=0.259$} & \multicolumn{3}{|c|}{$16.33, P=0.091$} & \multicolumn{3}{|c|}{$11.61, P=0.312$} \\
\hline AUROC $(95 \% \mathrm{CI})$ & \multirow{2}{*}{\multicolumn{3}{|c|}{$0.5232(0.5051-0.5413)$}} & \multirow{2}{*}{\multicolumn{3}{|c|}{$\begin{array}{l}0.5929(0.5754-0.6103), P<0.001^{\dagger} \\
1.28(1.04-1.53), P<0.001^{*}\end{array}$}} & \multirow{2}{*}{\multicolumn{3}{|c|}{$\begin{array}{l}0.6020(0.5848-0.6193), P<0.001^{\dagger} \\
1.54(1.27-1.80), P<0.001^{*}\end{array}$}} \\
\hline IDI, \% (95\% CI) & & & & & & & & & \\
\hline \multicolumn{10}{|l|}{ NEET, $61 \mathrm{~m}$} \\
\hline Lowest 10th & 7.4 & 5.3 & 0.72 & 5.3 & 5.6 & 1.05 & 3.4 & 3.1 & 0.94 \\
\hline 2nd & 6.3 & 5.8 & 0.93 & 7.2 & 5.8 & 0.81 & 3.6 & 3.7 & 1.04 \\
\hline $3 \mathrm{rd}$ & 5.8 & 6.2 & 1.06 & 5.9 & 6.1 & 1.03 & 2.8 & 4.1 & 1.49 \\
\hline 4 th & 5.1 & 6.5 & 1.26 & 6.4 & 6.3 & 0.99 & 4.3 & 4.5 & 1.07 \\
\hline 5 th & 5.5 & 6.6 & 1.21 & 8.0 & 6.5 & 0.82 & 5.1 & 5.0 & 0.97 \\
\hline 6 th & 5.4 & 6.8 & 1.25 & 5.3 & 6.7 & 1.26 & 5.2 & 5.6 & 1.07 \\
\hline 7 th & 5.6 & 7.0 & 1.26 & 6.7 & 7.0 & 1.04 & 7.9 & 6.5 & 0.83 \\
\hline 8 th & 7.5 & 7.3 & 0.98 & 7.3 & 7.3 & 1.01 & 10.2 & 8.1 & 0.80 \\
\hline 9 th & 7.3 & 7.8 & 1.07 & 7.0 & 7.7 & 1.10 & 9.3 & 10.4 & 1.11 \\
\hline Highest 10th & 11.6 & 8.6 & 0.74 & 9.4 & 8.8 & 0.93 & 15.4 & 15.9 & 1.04 \\
\hline Hosmer-Lemeshow chi-square* & \multicolumn{3}{|c|}{$24.43, P=0.007$} & \multicolumn{3}{|c|}{$8.06, P=0.623$} & \multicolumn{3}{|c|}{$12.87, P=0.231$} \\
\hline AUROC $(95 \% \mathrm{CI})$ & \multirow{2}{*}{\multicolumn{3}{|c|}{$0.5371(0.5104-0.5639)$}} & \multirow{2}{*}{\multicolumn{3}{|c|}{$\begin{array}{l}0.5347(0.5094-0.5601), P=0.904^{\dagger} \\
-0.01(-0.03 \text { to } 0.01), P<0.001^{*}\end{array}$}} & \multirow{2}{*}{\multicolumn{3}{|c|}{$\begin{array}{l}0.6607(0.6369-0.6845), P<0.001^{\dagger} \\
2.31(198-2.63), P<0.001^{\dagger}\end{array}$}} \\
\hline IDI, \% (95\% CI) & & & & & & & & & \\
\hline
\end{tabular}

Model 1: maternal age. Model 2: antenatal Edinburgh Postnatal Depression Scale score. Model 3: maternal age, highest education level, financial difficulties score, partner status, smoked in first 3 months of pregnancy, Edinburgh Postnatal Depression Scale score. NEET not in employment, education or training, and not had a baby since study child, AUROC area under receiver operator characteristic curve, IDI integrated discrimination improvement. ${ }^{*} P$ value tests null hypothesis that the predicted proportion equals the observed proportion within deciles. ${ }^{\dagger} P$ value tests null hypothesis that there is no difference in the AUROC of model 2 or 3 and model $1 .{ }^{\star} P$ value tests null hypothesis that IDI is not different from zero

at least one of the six predictors, and up to $45 \%$ would be identified among mothers with two or more of the six predictors. If pregnant women experiencing these characteristics could be engaged in effective programs many cases of poor outcomes could potentially be prevented. For example, if the $23 \%$ of pregnant women with two or more of the predictive characteristics were engaged in programs that were effective in encouraging and supporting breastfeeding, one-third of cases who would never have breastfed would potentially initiate breastfeeding.

Antenatal depression is, not surprisingly, a good predictor of postnatal depression, as they are potentially both part of the same illness episode [40, 41] and the majority of cases of postnatal depression in this cohort were preceded by antenatal depression [42]. Universal screening for depression is becoming available to all women in the perinatal period in Australia [43] and is recommended in the US [11], and if this information was used to identify the
$14 \%$ of pregnant women with antenatal depression and provide them with effective interventions, $43 \%$ of the cases of postnatal depression could potentially be prevented. As a predictor of poor maternal outcomes, depression during pregnancy, however, is not as sensitive as smoking and low education at identifying cases of poor maternal outcomes. Antenatal depression was associated with feelings of poor attachment and hostility toward the child, which might be considered part of the symptoms of depression, but was not associated with never breastfeeding or NEET after adjustment for other factors during pregnancy. The lack of an association between depressive symptoms during pregnancy and initiation of breastfeeding has been shown in previous studies [44, 45]. The high proportion (27\%) of women who never breastfed in this study is consistent with population figures, with 78\% of women in England in 2005 breastfeeding their babies after birth, and only $50 \%$ of all new mothers breastfeeding at week six [20]. 
The strengths of this study are the large sample size and longitudinal design with inclusion of a large number of relevant characteristics that could be routinely measured during pregnancy. Using self-reported smoking status may underestimate the prevalence of smoking among pregnant women [46], but self-reported smoking status still contributed to the prediction of poor maternal outcomes in this study and reflects the clinical situation in which pregnant women report their smoking status at antenatal consultations. Given that calibration cannot be assessed with a single binary predictor we used the continuous age variable, which may underestimate the poor calibration of maternal age with a cut-off less than 20 years, as is used in practice. Some evidence for this is supported by our sensitivity analyses in which we showed a lower AUROC when a binary measure of age was used rather than a continuous measure. Reduced power caused by cohort attrition is unlikely to be a major problem in a study of this size and analyses using multivariate multiple imputation produced similar results to complete case analyses, suggesting little bias due to missing data.

There are several issues that may influence the use of a broader range of predictive factors in routine clinical settings to more accurately identify mothers who are at high risk of poor outcomes, and who may be supported with enhanced perinatal care. First, collection of all of the characteristics would need to be feasible and acceptable to pregnant women. Information about depression, for example, is currently collected in some, but not all, settings [43]. Our study suggests that the majority of pregnant women provide information on the characteristics we have examined. Similar proportions of missing data have been shown in a clinic setting where forms completed by FNP nurses in the second wave pilot sites in England had missing data on educational status, marital status and smoking for $10.1 \%, 8.8 \%$ and $11.4 \%$ of enrolled women, respectively, though other predictors that we examined were not reported [47]. Second, there would need to be a simple tool for using the collected data and generating a 'risk' score for each individual. This could range from a simple checklist of predictors through to computer-based tools. With simple checklists, which would be feasible in most settings, women with one or two out of the list of six risk factors examined here could be considered for more intensive support programmes. Computer-based tools can make use of predictive risk algorithms containing continuous variables and are becoming increasingly common, for example in the prediction of cardiovascular disease risk and successful outcome with in vitro fertilisation (http://www.ivfpredict.com). Third, whilst there is some randomised controlled trial evidence that interventions are effective at improving some outcomes for certain groups of vulnerable mothers [48-51], it remains important to determine the effectiveness of programs on relevant outcomes among women identified using a larger number of predictive factors. Fourth, there would need to be available resources for providing programs to mothers identified at higher risk.

Improving outcomes among teenage mothers is important $[52,53]$, but focusing on this group alone will have little impact on improving depression, breastfeeding, feelings of poor attachment and hostility and reducing those not in employment, education or training among the overall population because maternal young age is not an adequate singular predictor, and few mothers with poor outcomes are teenagers. Other predictive factors such as maternal education level, smoking and depression during pregnancy, that have also been shown to be important predictors of child development outcomes [23], should be considered when offering women perinatal parent support programs.

Acknowledgments We are extremely grateful to all the families who took part in this study, the midwives for their help in recruiting them and the whole ALSPAC team, which includes interviewers, computer and laboratory technicians, clerical workers, research scientists, volunteers, managers, receptionists and nurses. The work in this paper is funded by a grant from the UK Economic and Social Research Council (RES-060-23-0011). The UK Medical Research Council (Grant ref: 74882), the Wellcome Trust (Grant ref: 076467) and the University of Bristol provide core support for ALSPAC. DAL works in a centre that receives support from the UK Medical Research Council (G0600705) and the University of Bristol. JWL is supported by an Australia Fellowship from the National Health and Medical Research Council of Australia. CRC is also supported by funds from the Australia Fellowship awarded to JWL. The funding bodies had no role in the decision to publish or the content of this article. The views expressed in this paper are those of the authors and not necessarily those of any of the funders. None of the funders influenced data collection, analyses or interpretation of results.

Open Access This article is distributed under the terms of the Creative Commons Attribution Noncommercial License which permits any noncommercial use, distribution, and reproduction in any medium, provided the original author(s) and source are credited.

\section{References}

1. The Marmot Review. (2010). Fair society, healthy lives. London: UK Department of Health.

2. Shribman, S., \& Billingham, K. (2009). Healthy child programme: Pregnancy and the first five years of life. London: UK Department of Health.

3. Berry, E., Brady, C., Cunningham, S. D., Derrick, L. L., Drummonds, M., Pettiford, B., et al. (2010). Federal healthy start initiative: A national network for effective home visitation and family support services. Washington, DC: National Healthy Start Association.

4. Council of Australian Governments (COAG). (2009). Investing in the early years-a national early childhood development strategy. Canberra: COAG.

5. Howard, K. S., \& Brooks-Gunn, J. (2009). The role of homevisiting programs in preventing child abuse and neglect. Future Child, 19, 119-146.

6. Barnes, J., Ball, M., Meadows, P., McLeish, J., Belsky, J., \& The FNP Implementation Research Team. (2008). Nurse-family 
partnership programme: First year pilot sites implementation in England. London: Institute for the Study of Children, Families and Social Issues, Birkbeck, University of London.

7. Olds, D., Kitzman, H., Cole, R., \& Robinson, J. (1997). Theoretical foundations of a program of home visitation for pregnant women and parents of young children. Journal of Community Psychology, 25, 9-25.

8. Lynch, J. W., Law, C., Brinkman, S., Chittleborough, C., \& Sawyer, M. (2010). Inequalities in child healthy development: Some challenges for effective implementation. Social Science and Medicine, 71, 1244-1248.

9. Children, Youth and Women's Health Service. (2005). Family home visiting. Service outline. Adelaide: Children, Youth and Women's Health Service.

10. Hall, D., \& Hall, S. (2007). The "family-nurse partnership": Developing an instrument for identification, assessment and recruitment of clients. London: Department for Children, Schools and Families.

11. Earls, M. F. (2010). The committee on psychosocial aspects of child and family health. Incorporating recognition and management of perinatal and postpartum depression into pediatric practice. Pediatrics, 126, 1032-1039.

12. Mollborn, S., \& Morningstar, E. (2009). Investigating the relationship between teenage childbearing and psychological distress using longitudinal evidence. Journal of Health and Social Behavior, 50, 310-326.

13. Brand, S. R., \& Brennan, P. A. (2009). Impact of antenatal and postpartum maternal mental illness: How are the children? Clinical Obstetrics and Gynecology, 52, 441-455.

14. Moehler, E., Brunner, R., Wiebel, A., Reck, C., \& Resch, F. (2006). Maternal depressive symptoms in the postnatal period are associated with long-term impairment of mother-child bonding. Archives of Women's Mental Health, 9, 273-278.

15. Cornish, A. M., McMahon, C. A., Ungerer, J. A., Barnett, B., Kowalenko, N., \& Tennant, C. (2006). Maternal depression and the experience of parenting in the second postnatal year. Journal of Reproductive and Infant Psychology, 24, 121-132.

16. Wan, M., \& Green, J. (2009). The impact of maternal psychopathology on child-mother attachment. Archives of Women's Mental Health, 12, 123-134.

17. Kiernan, K. E., \& Huerta, M. C. (2008). Economic deprivation, maternal depression, parenting and children's cognitive and emotional development in early childhood. The British Journal of Sociology, 59, 783-806.

18. Augustine, J. M., \& Crosnoe, R. (2010). Mothers' depression and educational attainment and their children's academic trajectories. Journal of Health and Social Behavior, 51, 274-290.

19. World Health Organization. (2009). Infant and young child feeding: Model chapter for textbooks for medical students and allied health professionals. Geneva: WHO.

20. Bolling, K., Grant, C., Hamlyn, B., \& Thornton, A. (2007). Infant feeding survey 2005. London: The Information Centre, Department of Health.

21. Dennis, C. L., \& McQueen, K. (2009). The relationship between infant-feeding outcomes and postpartum depression: A qualitative systematic review. Pediatrics, 123, e736-e751.

22. Wald, N. J., Hackshaw, A. K., \& Frost, C. D. (1999). When can a risk factor be used as a worthwhile screening test? BMJ, 319, 1562-1565.

23. Chittleborough, C. R., Lawlor, D. A., \& Lynch, J. W. (2011). Young maternal age and poor child development outcomes by age 5: findings on predictive validity from a longitudinal birth cohort. Pediatrics, 2010-3222 (in press). doi:10.1542/peds.

24. Golding, J., Pembrey, M., Jones, R., \& ALSPAC Study Team. (2001). ALSPAC: the Avon longitudinal study of parents and children. I. Study methodology. Paediatric and Perinatal Epidemiology, 15, 74-87.
25. Cox, J. L., Holden, J. M., \& Sagovsky, R. (1987). Development of the Edinburgh Postnatal Depression Scale. British Journal of Psychiatry, 150, 782-786.

26. Evans, J., Heron, J., Francomb, H., Oke, S., \& Golding, J. (2001). Cohort study of depressed mood during pregnancy and after childbirth. BMJ, 323, 257-260.

27. Murray, L., \& Carrothers, A. D. (1990). The validation of the Edinburgh Postnatal Depression Scale on a community sample. British Journal of Psychiatry, 157, 288-290.

28. World Health Organization. (2008). Indicators for assessing infant and young child feeding practices. Part I: definition. Conclusions of a consensus meeting held 6-8 November 2007. Washington, DC, USA, Geneva: WHO.

29. Waylen, A., Stallard, N., \& Stewart-Brown, S. (2008). Parenting and health in mid-childhood: A longitudinal study. European Journal of Public Health, 18, 300-305.

30. Bowen, E., Heron, J., Waylen, A., \& Wolke, D. (2005). Domestic violence risk during and after pregnancy: Findings from a British longitudinal study. BJOG, 112, 1083-1089.

31. Murray, D., \& Cox, J. L. (1990). Screening for depression during pregnancy with the Edinburgh depression scale (EPDS). Journal of Reproductive and Infant Psychology, 8, 99-107.

32. Thorpe, K. (1993). A study of the Edinburgh Postnatal Depression Scale for use with parent groups outside the postpartum period. Journal of Reproductive and Infant Psychology, 11, 119-125.

33. Steyerberg, E. W., Vickers, A. J., Cook, N. R., Gerds, T., Gonen, M., Obuchowski, N., et al. (2010). Assessing the performance of prediction models. A framework for traditional and novel measures. Epidemiology, 21, 128-138.

34. Pencina, M. J., D’Agostino, R. B., Sr., D'Agostino, R. B., Jr., \& Vasan, R. S. (2008). Evaluating the added predictive ability of a new marker: From area under the ROC curve to reclassification and beyond. Statistics in Medicine, 27, 157-172.

35. Royston, P. (2004). Multiple imputation of missing values. The Stata Journal, 4, 227-241.

36. Office for National Statistics. (2010). Births in England and Wales 2009. Accessed October 1, 2010. www.statistics.gov.uk/ statbase/Product.asp?vlnk=14408.

37. Martin, J. A., Hamilton, B. E., Sutton, P. D., Ventura, S. J., Menacker, F., Kirmeyer, S., et al. (2009). Births: Final data for 2006. National Vital Statistics Report, Vol 57, No. 7. Hyattsville, MD: National Center for Health Statistics.

38. Australian Bureau of Statistics. (2009). Births 2008. Catalogue No. 3301.0. Canberra: Australian Bureau of Statistics.

39. Office for National Statistics. (2006). Statistics on smoking: England, 2006. Accessed December 15, 2010. http://www.ic.nhs. uk/webfiles/publications/smokingeng2006/StatisticsOnSmoking 300806_PDF.pdf.

40. Hayes, B. A. (2010). From 'postnatal depression' to 'perinatal anxiety and depression': Key points of the National Perinatal Depression Plan for nurses and midwives in Australian primary health care settings. Contemporary Nurse, 35, 58-67.

41. Robertson, E., Grace, S., Wallington, T., \& Stewart, D. E. (2004). Antenatal risk factors for postpartum depression: A synthesis of recent literature. General Hospital Psychiatry, 26, 289-295.

42. Heron, J., O'Connor, T. G., Evans, J., Golding, J., \& Glover, V. (2004). The course of anxiety and depression through pregnancy and the postpartum in a community sample. Journal of Affective Disorders, 80, 65-73.

43. Australian Government. (2009). Framework for the National Perinatal Depression Initiative 2008-2009 to 2012-2013. Canberra: Australian Government.

44. Bogen, D. L., Hanusa, B. H., Moses-Kolko, E., \& Wisner, K. L. (2010). Are maternal depression or symptom severity associated with breastfeeding intention or outcomes? The Journal of Clinical Psychiatry, 71, 1069-1078. 
45. Fairlie, T. G., Gillman, M. W., \& Rich-Edwards, J. (2009). High pregnancy-related anxiety and prenatal depressive symptoms as predictors of intention to breastfeed and breastfeeding initiation. Journal of Women's Health (Larchmt), 18, 945-953.

46. Shipton, D., Tappin, D. M., Vadiveloo, T., Crossley, J. A., Aitken, D. A., \& Chalmers, J. (2009). Reliability of self reported smoking status by pregnant women for estimating smoking prevalence: A retrospective, cross sectional study. BMJ, 339, b4347.

47. Barnes, J., Ball, M., Meadows, P., \& Belsky, J. (2009). Nursefamily partnership programme. Second year pilot sites implementation in England. The infancy period. London: Institute for the Study of Children, Families and Social Issues, Birkbeck, University of London.

48. Olds, D. L., Henderson, C. R., Jr., Tatelbaum, R., \& Chamberlin, R. (1988). Improving the life-course development of socially disadvantaged mothers: A randomized trial of nurse home visitation. American Journal of Public Health, 78, 1436-1445.

49. Olds, D. L., Henderson, C. R., Jr., \& Kitzman, H. (1994). Does prenatal and infancy nurse home visitation have enduring effects on qualities of parental caregiving and child health at 25 to 50 months of life? Pediatrics, 93, 89-98.

50. Olds, D. L., Robinson, J., O'Brien, R., Luckey, D. W., Pettitt, L. M., Henderson, C. R., Jr., et al. (2002). Home visiting by paraprofessionals and by nurses: A randomized, controlled trial. Pediatrics, 110, 486-496.

51. Olds, D. L., Kitzman, H., Cole, R., Robinson, J., Sidora, K., Luckey, D. W., et al. (2004). Effects of nurse home-visiting on maternal life course and child development: Age 6 follow-up results of a randomized trial. Pediatrics, 114, 1550-1559.

52. de Jonge, A. (2001). Support for teenage mothers: a qualitative study into the views of women about the support they received as teenage mothers. Journal of Advanced Nursing, 36, 49-57.

53. Department for Children Schools, Families. (2008). Teenage parents: Who cares? Nottingham: Department for Children, Schools and Families. 